\title{
TRANSCRIPTOME AND CHEMICAL ANALYSIS OF HEALTHY AND INFECTED STEMS OF AQUILARIA MALACCENSIS
}

\author{
Aimi-Wahidah $\mathbf{A}^{1}$, Rofiza $\mathbf{M}^{2}$, Saiful-Nizam $\mathbf{T}^{2}$ \& Aizi-Nor-Mazila $\mathbf{R}^{1,2, *}$ \\ ${ }^{1}$ Faculty of Industrial Science E Technology, Universiti Malaysia Pahang, Lebuhraya Tun Razak, 26300 Gambang, \\ Kuantan, Pahang Darul Makmur, Malaysia \\ ${ }^{2}$ Bio Aromatic Research Centre of Excellence, Universiti Malaysia Pahang, Lebuhraya Tun Razak, 26300 Gambang, \\ Kuantan, Pahang Darul Makmur, Malaysia \\ *aizinor@ump.edu.my
}

Submitted September 2020; accepted January 2021

\begin{abstract}
Aquilaria genus is an important source of agarwood and is widely used as incense, perfumery and ingredients in traditional medicines. The study investigated the genes and pathways controlling the molecular mechanism of A. malaccensis agarwood under controlled environment. Two transcriptome libraries were sequenced from mRNAs of both healthy and infected stem samples of A. malaccensis using Illumina sequencing. Total of 10,734,590 and 8,298,918 reads for both infected stems libraries and 6,274,184 reads for healthy stem library were identified. A total of 370,707 unigenes were functionally annotated using the gene ontology analysis. Infected white stem recorded higher reading of unigenes distribution in process related to plant defence mechanism compared to healthy stem. The de novo assembly and the gene ontology annotation data suggested that the infected white stem involved in plant defence response and produced agarwood compound. This study provided promising and valuable sequence resources for future genomic studies from stem of A. malaccensis as well as in depth study on molecular mechanism of agarwood formation and plant related defence responses.
\end{abstract}

Keywords: agarwood, sesquiterpenes, transcriptomic, unigenes, A. malaccensis

\section{INTRODUCTION}

Aquilaria or karas trees is from the family Thymelaeaceae. It is known as an important source of agarwood production (Chong et al. 2015). Currently, 21 species were documented and is well distributed in India, China, Papua New Guinea and South East Asia (Huda et al. 2009). Several species of Aquilaria such as Aquilaria crassna, Aquilaria sinensis and Aquilaria malaccensis are known as agarwood producing plants. Among them, A. malaccensis is an industrial crop in Malaysia and known as the major agarwood producer from Aquilaria sp. (Elias et al. 2017). Agarwood, the resinous wood of Aquilaria was used since ancient times as incense, ingredient for perfumes and as traditional medicines in many cultures (Nor-Fazila \& Ku-Halim 2012, Selvan \& Kaushik-Pawan 2014). High demand of agarwood has led to uncontrolled harvesting activity of wild agarwood trees in the forest. This situation has caused the agarwood market to experience shortage of resources. Thus leading to greater efforts in conservation and further research on the formation of agarwood by natural and artificial means (Saikia \& Khan 2011). Aquilaria has been listed in Appendix II of the Convention on International Trade in Endangered Species (CITES) due to serious depletion in the agarwood resources.

The quality of agarwood is identified by scientific analysis to determine the presence of chemical constituents in agarwood. Agarwood contains marker sesquiterpene compounds such as agarospirol, kusunol and jinkoh-eremol. They give agarwood its signature scent of woody and sweet aroma (Tajuddin et al. 2008, Liu et al. 2017). The production of agarwood is unable to meet the demand of the growing market. Agarwood formation took at least 3 to 4 years to meet the general quality standard while high grade agarwood took more than 10 years and limited in yield (Zhang et al. 2010, Wu et al. 2017, Chhipa \& Kaushik 2017). Agarwood price is determined by its grade (Nor-Azah et al. 2013). 
The formation of agarwood is also uncertain and unpredictable. The natural formation of agarwood involves microbial invasion in several factors such as physical wound, pathogenic attack and animal grazing, gnawing of insects, lightning strikes and heavy winds (Pojanagaroon \& Kaewrak 2005, Zhang et al. 2014, Chhipa \& Kaushik 2017). The internal plant protection system secretes resin as protection to the disturbances because resin contains antimicrobial and antiinflammatory properties (Chen et al. 2011, Wang et al. 2018) . The molecular mechanism of resin formation and related defence responses in agarwood remain largely unknown. Moreover, the defence mechanism towards stress such as pathogenic infection and mechanical injury is yet to be identified.

Transcriptome sequencing is an effective technique to unravel novel genes and molecular markers (Han et al. 2013). Illumina sequencing technology can be applied as a rapid method to accelerate research towards de novo transcriptome analysis of non-model plants with unavailable genomic information. Currently, predicting the number of genes and the potential functions of the unigenes are important parameters in the transcriptome sequencing technology (Han et al. 2013). Quality short reads and read length by paired-end sequencing can be effectively assembled and also successfully developed for plant based study with no genomic sequence (Han et al. 2013). Prior to this research work, limited A. malaccensis reference sequences were reported in the public databases and sequence data were insufficient.

This study aimed to elucidate the transcriptomic data of A. malaccensis using infected and healthy stem samples and to compare the regulatory genes during the activation of plant immunity in different sample regions. A healthy stem and two types of infected stems of A. malaccensis were analysed involving dark and white parts collected from the same wounded area. RNA sequencing technology were used to generate profile transcriptomic data of A. malaccensis using Illumina MiSeq platform. The finding provided valuable sequence resources for future genomic studies on the stem of $A$. malaccensis and further identified the potential agarwood compound formation in infected stem of A. malaccensis.

\section{MATERIALS AND METHODS}

\section{Samples collection and preparation}

Three different Aquilaria samples such as healthy stem, infected black stem and infected white stem were collected from the Karas Farm of the Terengganu State Forestry Department at Merchang, Malaysia. All samples were wrapped, labelled in aluminium foil and stored in $-196{ }^{\circ} \mathrm{C}$ liquid nitrogen to avoid degradation of RNA by RNAse reaction during transportation. The samples were then maintained in the laboratory freezer at $-80{ }^{\circ} \mathrm{C}$ until further use.

\section{Total RNA Extraction}

Total RNA was successfully extracted from infected black stems, infected white stems and healthy stems of $A$. malaccensis using RNaqueous ${ }^{\circledR}$ and Ribospin ${ }^{\mathrm{TM}}$ plant extraction kits with some manual modifications. Total RNA was subjected to quality control analysis by checking their purity at wavelengths of A260/280 and A230/280 and concentration using Nanodrop spectrophotometer. The RNA band was detected after running $1 \%$ agarose gel with 7 Volt electrophoresis for 40 minutes. Total RNA was purified using DNase free kit to remove excess DNA present in the extracted total RNA. Purified total RNA was later analysed using a Bioanalyzer to obtain the RNA integrity number which corresponded to the purity of RNA (Schroeder et al. 2006).

\section{Preparation of cDNA Library}

The master mix for cDNA Library preparation which consisted of cDNA Synthesis PreMix, 100 mM DTT and StarScript Reverse Transcriptase were prepared using ScriptSeq-V2 RNA-Seq Library preparation kit, Illumina Library Index and incubated at $85{ }^{\circ} \mathrm{C}$ for 5 minutes in the thermocycle for fragmentation of RNA. The mixture was later placed on ice to stop the fragmentation. The mixture was incubated in Real-Time PCR detection system at $25{ }^{\circ} \mathrm{C}$ for 5 minutes and $42{ }^{\circ} \mathrm{C}$ for 20 minutes for cDNA synthesis. The mixture was incubated at $37{ }^{\circ} \mathrm{C}$ for 10 minutes for the finishing solution reaction and proceeded for inactivation of finishing solution at $95{ }^{\circ} \mathrm{C}$ for 3 minutes. The master 
mix was prepared by mixing $7.5 \mu \mathrm{l}$ of Terminal Tagging Master Mix with $0.5 \mu \mathrm{l}$ DNA polymerase. The master mix was then added into the sample and gently mixed by pipetting before the mixture was incubated at $25{ }^{\circ} \mathrm{C}$ for 15 minutes for DNA polymerase reaction and followed by $95{ }^{\circ} \mathrm{C}$ for 3 minutes for DNA polymerase inactivation. The mixture was then placed on ice to stop the reaction. The cDNA was now a di-tagged form and proceeded for purification by using the Agencourt RNAClean XP kit.

KAPA Library Quantification kit was used to amplify the number of the library and index barcode was added on each of samples through quantification Real-Time PCR (qRTPCR) under the thermal cycler. The process involved incubation at $95{ }^{\circ} \mathrm{C}$ for 1 minutes, followed by 13 cycles of $95{ }^{\circ} \mathrm{C}$ for 30 seconds, $55{ }^{\circ} \mathrm{C}$ for 30 seconds, $68{ }^{\circ} \mathrm{C}$ for 3 minutes and the final extension was at $72{ }^{\circ} \mathrm{C}$ for 5 minutes. The library was tagged with Illumina adaptor sequences barcode. The PCR premix consisted of PCR PreMix E, forward PCR primer $(2 \mu \mathrm{M})$, reverse PCR primer $(2 \mu \mathrm{M})$ and PCR enzyme and cDNA was also prepared. Subsequently, the prepared libraries were purified by using Agencourt RNAClean XP kit. The library was prepared with 4 dilutions at the ratio of 1:1000 and 1:2000. The buffer used in the library dilution contained mixture of $10 \mathrm{mM}$ Tris-HCl $(\mathrm{pH} 8.0)+0.05 \%$ Tween ${ }^{\circledR} 20$. The master mix and pre-mix for the diluted library including the fast master mix together with primer premix, water and the diluted library/DNA standard $(\mathrm{pM})$ were also prepared. The diluted library was amplified in real-time PCR at $95{ }^{\circ} \mathrm{C}$ for 5 minutes, followed by $95{ }^{\circ} \mathrm{C}$ for 30 seconds for separation of nucleic acid double chain, $60{ }^{\circ} \mathrm{C}$ for 45 seconds for binding of the primer with DNA template and the final extension was at $68^{\circ} \mathrm{C}$ for 5 minutes. In order to facilitate polymerisation by DNA polymerase, the protocol was repeated for 35 cycles. The amplification of the cDNA was calculated by increasing the Delta-delta Ct method in the threshold cycle. The cDNA was lastly sent for transcriptomic sequencing using Illumina platform.

\section{Sequence analysis of transcriptome data of infected and healthy $A$. malaccensis}

Trinity de novo assembly programme was used to assemble the next generation short reads sequence from raw data. Sequence assembly analysis of transcriptome data of infected black stems, infected white stems and healthy stems of $A$. malaccensis was carried out using the CLC Genomics Workbench software to identify the contigs and the singletons. The sequences were subjected to functional analysis through BLASTX tool at NCBI database and also protein prediction with the reference to protein databases. Gene annotation was carried out using BLAST2GO software together with Gene Ontology database for biological function and classification including biological process, molecular function and cellular components. The transcriptomic data was submitted to NCBI and the accession numbers will be recorded once available.

\section{Comparison of chemical profile between infected and healthy $A$. malaccensis using Solid Phase Micro-Extraction mechanism}

The infected black, infected white and healthy stems were collected at the same growing period as the samples collected for RNA extraction. The stems were initially dried at $40{ }^{\circ} \mathrm{C}$ for 7 days to remove moisture. An amount of $0.5 \mathrm{~g}$ of each sample was cut into small pieces and transferred into a $20 \mathrm{ml}$ head-space vial. The sample and control vials were heated at $50{ }^{\circ} \mathrm{C}$ for 30 minutes and the volatiles were captured using Solid Phase Micro-Extraction device containing silica fibre coated with $100 \mu \mathrm{m}$ polydimethylsiloxane for 30 minutes.

\section{Comparison of chemical profile between infected and healthy $A$. malaccensis using Gas Chromatography-Flame Ion Detector}

The infected black, infected white and healthy stems samples were manually injected into Flame Ionization Detector Gas Chromatography-Mass Spectrometry and were separated using a $30 \mathrm{~m}$ size capillary DB-1 column using helium as carrier gas. The front inlet was run with the splitless mode, the heater at $200{ }^{\circ} \mathrm{C}$ with pressure of 12.537 psi and the septum purge flow at the rate of $3 \mathrm{ml} \mathrm{min}^{-1}$. The oven initial temperature was at $80{ }^{\circ} \mathrm{C}$ with the flow rate of $1 \mathrm{ml} \mathrm{min}^{-1}$ and the ramp rate of $5{ }^{\circ} \mathrm{C} \mathrm{min}^{-1}$ at $250{ }^{\circ} \mathrm{C}$ with holding time of 5 minutes. The front detector heater was set at $250{ }^{\circ} \mathrm{C}$ with the hydrogen flow rate of $35 \mathrm{ml} \mathrm{min}{ }^{-1}$ and air flow rate of $350 \mathrm{ml} \mathrm{min}^{-1}$. The 
collected volatility profiles for both infected and healthy samples were compared with National Institute of Standards and Technology Spectral Library and standard commercial fragrance compounds (Ismail et al. 2013, Ahmaed et al. 2017). The data from Gas ChromatographyFlame Ion Detector were calculated to obtain the Kovats retention index for each identified compound.

\section{RESULTS AND DISCUSSIONS}

\section{De novo assembly and analysis}

A total number of $29,635,188$ raw reads were generated with 12,530,734 reads represented the infected black region stem, 9,734,678 reads for the infected white region stem and 7,369,776 reads for the. The total reads were later filtered for high quality data with quality score of $Q \geq 30$ and in the absence of ambiguous $\mathrm{N}$ region. As a result, the high quality reads for infected black region stem was $10,734,590$ reads $(85.67 \%$ of raw data reads), infected white region stem at $8,298,918$ reads $(85.25 \%$ of raw data reads) and healthy stem with $6,274,184$ reads $(85.13 \%$ of raw data reads) (Table 1 )

Only high quality reads were subjected to $d e$ novo transcriptome assembly. After the removal of adaptor sequences, contaminated and short reads, the 25,307,692 high quality reads were assembled into 412,138 contigs. Trinity de novo assembly program generated 177,356 , 97,735 and 95,616 unigenes for infected black, infected white and healthy stems respectively. A total of 370,707 unigenes were obtained after combining all reads. The total reads generated from the Illumina Sequencing were promising and acceptable as compared to the transcriptome data of $A$. sinensis which reported the raw reads data collected were lower than the present data (Xu et al. 2013). The results recorded were only 565,008 and 562,060 reads for infected and healthy samples respectively with high quality reads for infected stems at 543,031 reads $(96.11 \%$ of the raw data) and healthy stems at 530,438 reads $(94.37 \%$ of the raw data) (Xu et al. 2013).

\section{Annotation of the assembled unigenes}

Gene ontology for each sample was conducted using BLAST2GO software to classify and to arrange the particular functions on the assembled transcripts. The total of 370,707 unigenes of infected black, infected white and healthy stems that showed significant BLAST alignments with non-redundant protein database were assigned for gene ontology annotation. In this study, the gene ontology annotation was classified into three different categories such as cellular components, molecular functions and biological process. The annotated data represented approximately 180,453 unigenes in cellular components, 90,999 unigenes in molecular functions and 99,255 in biological process. When compared with previous transcriptomic data from the callus tissue of A. malaccensis using the same platform, the total number of unigenes detected was 231,594 which was lower than the result obtained from this finding. The percentage of gene ontology categories for callus tissue of A. malaccensis showed $50.7 \%$ for biological processes, $24.0 \%$ for molecular functions and $25.3 \%$ for cellular components (Siah et al. 2016). The unigenes distribution in biological processes was higher at $50.7 \%$ than the data for the current study at $48.68 \%$, probably due to the callus condition in culture medium had responded to the abiotic stress and consequently activated the immune response (Siah et al. 2016). Figure 1 showed the respective percentage of gene ontology categories for whole samples collected representing $26.77 \%$ in cellular components, $24.55 \%$ in molecular functions and $48.68 \%$ in biological process prior to their relatively conserved functions. The distribution of gene functions was assigned based

Table 1 Total of sequence reads in A. malaccensis cDNA library

\begin{tabular}{lccc}
\hline Sample & RAW reads & High quality reads & \% High quality reads \\
\hline Infected black & $12,530,734$ & $10,734,590$ & 85.67 \\
Infected white & $9,734,678$ & $8,298,918$ & 85.25 \\
Healthy & $7,369,776$ & $6,274,184$ & 85.13 \\
\hline Total & $29,635,188$ & $25,307,692$ & 85.40 \\
\hline
\end{tabular}




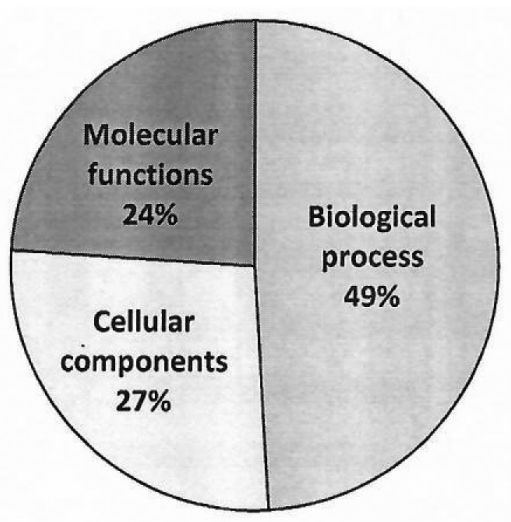

Figure 1 Gene ontology classification of the assembled transcripts

on three main gene ontology categories for better assessment of gene ontology annotation.

The number of $A$. malaccensis unigenes involved in biological process showed metabolic process and cellular process were highly represented in this category (Figure 2). Based on the distribution of unigenes, infected black stem recorded the highest distribution numbers followed by infected white stem and the least was healthy stem. The number of unigenes for all the processes involved in biological process was highly regulated in the infected black stem which was at $47.6 \%$ compare to infected white stem and healthy stem at $26.4 \%$ and $25.8 \%$ respectively. The highly regulated unigenes in both infected samples were similar with the previous finding of A. malaccensis transcriptomic data from callus tissue with the percentage value of unigenes recorded at $28.6 \%$ compared to healthy sample at $21.3 \%$. Based on the distribution of unigenes, infected black stem recorded the highest distribution numbers followed by infected white stem and the least was healthy stem. In biological process, both infected samples showed large number of unigenes responsible for the response to stimulus due to the reaction of plant defence and fungi infection. The defence mechanism triggered by plant stress in turn initiated the secondary metabolite biosynthesis in the form of agarwood resin accumulation (Tan et al. 2019). The molecular function component in the gene ontology category recorded high binding and catalytic activity in infected black stem which dominated in the most distributed genes, followed by infected white and healthy stems (Figure 3). The high amount of unigenes involved in the binding and the catalytic activity indicated the presence of diverse types of secondary metabolites and composite regulation mechanism in agarwood production (Ye et al. 2016). The observed infected black stem was the part affected by certain infection or fungal reaction. The highly regulated plant processes indicated that infection had stimulated the plant defence mechanism to trigger the plant mevalonate pathway and to discharge resin as a reaction against the particular fungi (Nagajothi \& Parthiban 2016).

A total of 99,255 unigenes of A. malaccensis were involved in the cellular components category where the regulated genes were abundance in the

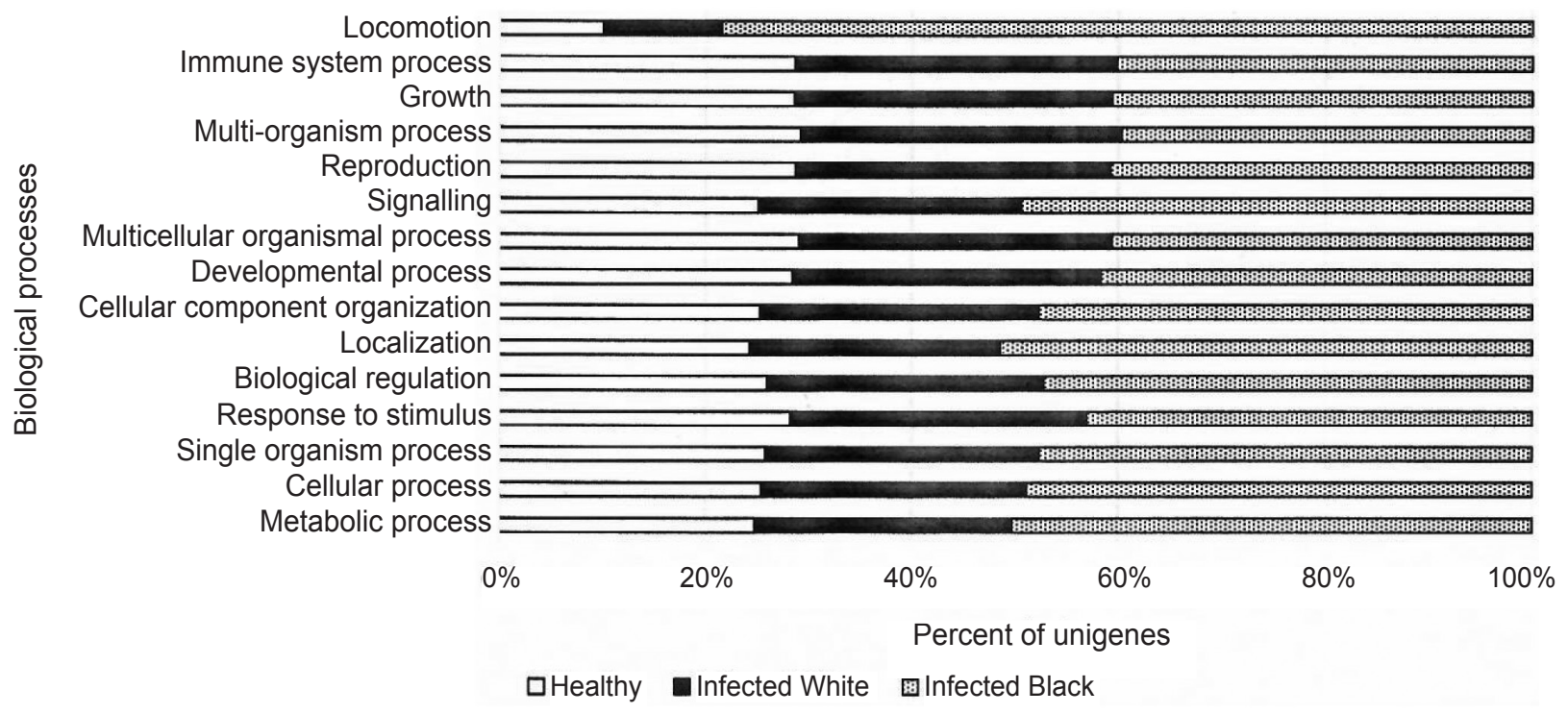

Figure 2 Percentage of unigenes distribution in biological processes 
infected black stem as compared to infected white and healthy stems (Figure 4). The distribution accounted for the most unigenes and were highly expressed in cell, organelle, membrane and macromolecular complex. The parallel results for all three gene ontology categories indicated that most of the sequenced genes were responsible for essential plant metabolism and regulation
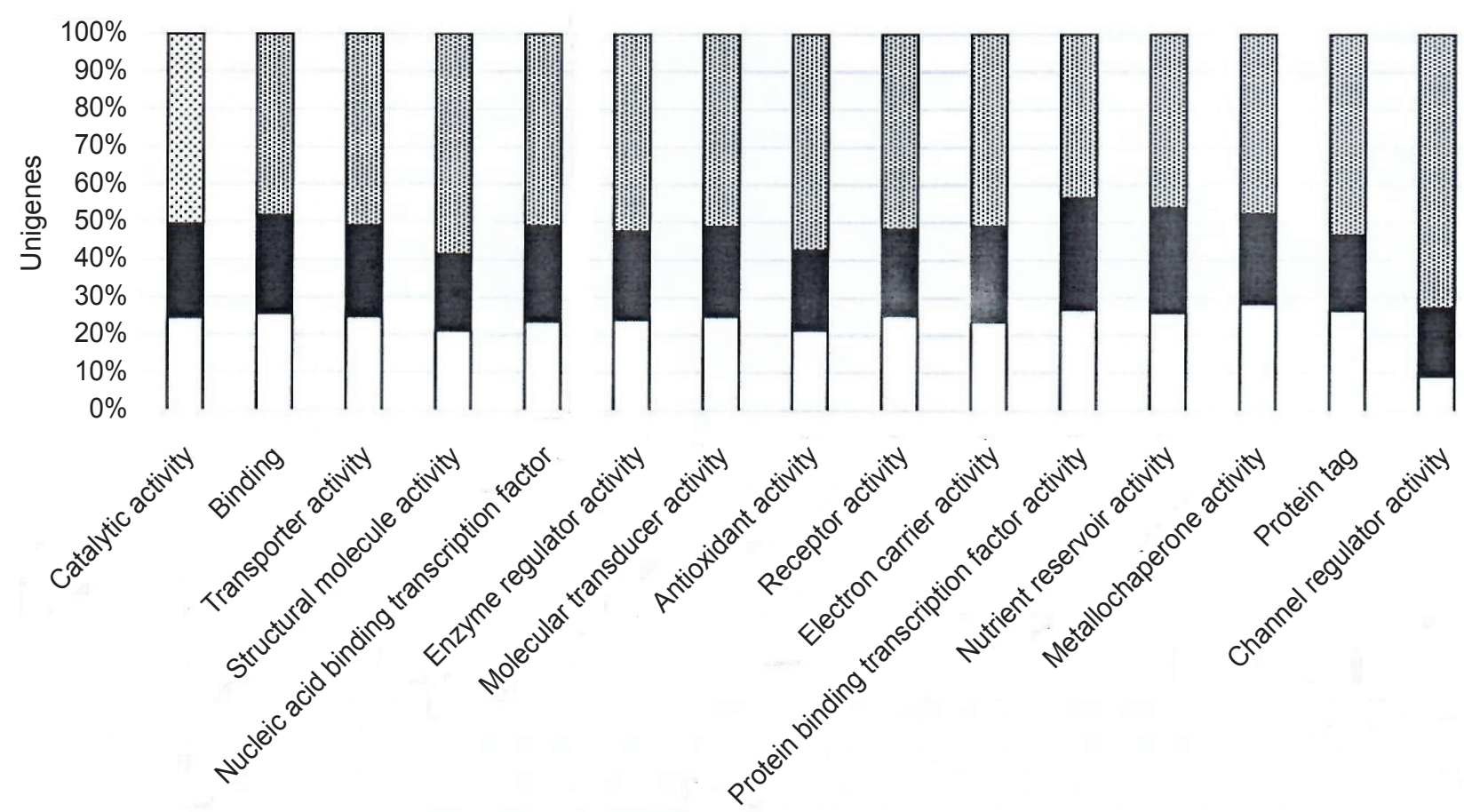

Molecular functions

$\square$ Healthy Infected White Infected Black

Figure 3 Distribution of unigenes assembly in molecular functions

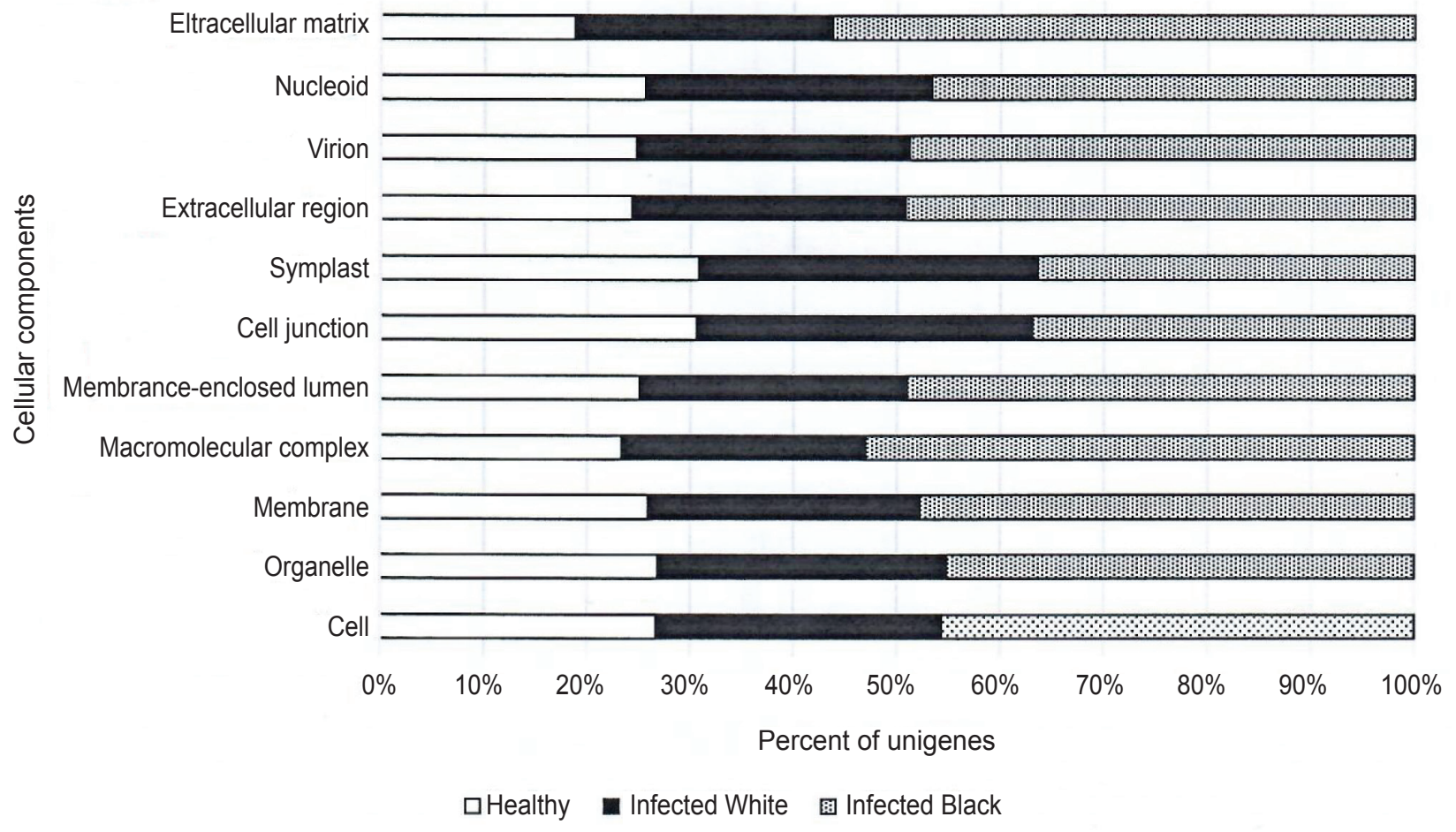

Figure 4 Distribution of unigenes assembly in cellular components 
(Han et al. 2013). In cellular component category, the infected stems recorded higher distributed unigenes compared to the healthy stem indicated. The higher distributed unigenes indicated that the whole plant mechanism and processes were interrelated as each of the cell reaction was upregulated when under stress condition.

Cell and organelle also showed the highest gene regulation in infected black stem with 16,023 and 11,893 reads respectively compared to infected white and healthy stems. It was suggested that the cellular components played major role in protecting the plant system from further harmful factors (Ye et al. 2016). Prior to agarwood formation, the abundant secondary metabolite constituents in agarwood such as sesquiterpenoids were produced during secretion of resin as plant defence products. The metabolites in agarwood acted as protective compound with antimicrobial and disease prevention properties (Chen et al. 2011, Xu et al. 2017).

\section{Regulated gene in A. malaccensis}

The number of regulated unigenes involved in the plant defence mechanism in response to stimulus, immune system process, enzyme regulator activity and to stress for each sample of A. malaccensis which were summarized in Table 2. The infected black and white stems indicated higher readings for all molecular functions which was closely related to the agarwood formation pathways, as compared to the lower readings of the healthy stems. However, enzyme regulator activity values appeared to be contradictory to the findings as the infected white stems had lower reads compared to healthy stems at 242 and 249 respectively.

This study found that the activation of cell death phase in the infected white stem was probably due to the hypersensitive response in the host pathogen interaction which promoted the infected tissue to progress to cell death. It was verified by the higher immunity system process readings in the infected white stems as compared to healthy stems (Thakur \& Sohal 2013). Similar result was observed from previous $A$. malaccensis transcriptomic data of leaf samples where the number of genes involved in enzymatic pathways of agarwood formation was lower in senescing tissue compared to healthy tissue (Siah et al. 2016). From the recorded data, it was assumed that there was cell-to-cell relationship through the activation of nervous interfering components which acted in the form of chemical transmitters (Mazid et al. 2011). Protein-mediated cell communication functioned through the systemic to signal the quick release immunity responses in infected region of the plant (Siah et al. 2016).

The unaffected wood was relatively light in colour because healthy wood of Aquilaria trees lack oleoresins (Chong et al. 2015, Nagajothi \& Parthiban 2016). In most agarwood studies, the main focus was on the dark region of the infected wood while the light colour region of the infected wood of Aquilaria was almost neglected. In natural conditions, oleoresin was only produce by natural wounding such as injury by lightning or animals and was typically found around the wounded or rotting parts of the trunk (Pojanagaroon \& Kaewrak 2005, Chong et al. 2015). Based on the transcriptome analysis, the infected white stems recorded higher reading of unigenes distribution in all gene ontology data categories such as biological processes, molecular function and cellular components as compared to healthy stems. The observations suggested that the infected white region was also involved in plant defence response to produce agarwood compound. In the formation of agarwood, the resin secreted after plant defence response was triggered by fungal infection at both dark and white infected regions (Mohamed et al. 2010). Resin continued to accumulate in

Table 2 Summary of regulated genes toward processes occurred in plant defence system

\begin{tabular}{lccc}
\hline Molecular function & \multicolumn{3}{c}{ Number of unigenes } \\
\cline { 2 - 4 } & Infected black & Infected white & Healthy \\
\hline Response to stimulus & 5756 & 3840 & 3772 \\
Response to stress & 3024 & 2155 & 2093 \\
Enzyme regulator activity & 541 & 242 & 249 \\
Immune system process & 377 & 293 & 269 \\
\hline
\end{tabular}


wood tissue as the injury prolonged with the pathogenic infection (Tajuddin et al. 2008). The records suggested that agarwood formation in A. malaccensis stem samples was the result of plant defence mechanism towards fungal attacks by secreting resinous compounds as secondary metabolite (Mohamed et al. 2010, Nagajothi \& Parthiban 2016). The finding by Mohamed et al. (2010) supported this outcome by which they successfully isolated Fusarium sp. and Lasiodiplodia sp. from both dark and white infected wood regions. Physical wounds on plant regulated a number of genes unique to plants which played important roles in pathogen response for instance proteinase inhibitors, secondary metabolites, transcription factors such as DNA binding proteins with WRKY domains and defence genes such as pathogenesis-related genes (Wong \& Siah 2013).

Plants reacted to pathogen attack by activating the pathogenesis-related proteins such as $\beta$-1,3-glucanases which was known to be induced during fungal infection together with chitinase. The natural response inhibited fungal growth by dissolving the germ tube tips and fungal hyphae to enhance resistance toward fungi attack (Van-Loon et al. 2006, Liu et al. 2010, Wong \& Siah 2013). Some components of fungi triggered the host cell to generate a signal transduction network leading to the activation of transcription factors. It then regulated the expression of biosynthetic genes which catalysed the biosynthesis of target secondary metabolites (Zhao et al. 2005, Cui et al. 2013, Wang et al. 2018). Fungi could act as elicitors which stimulated the accumulation of plant secondary metabolites, enhanced the host plant defence and promoted the host plant growth (Selosse et al. 2004, Chen et al. 2010, Koffi et al. 2012, Cui et al. 2013). The role of fungi in eliciting resin production was eminent as more than a dozen varieties or genetic strains of fungi such as Phomopsis sp., Botryosphaeria sp., Cylindrocladium sp. and Colletotrichum gloeosporioides were isolated from the infected Aquilaria tree (Tabata et al. 2003, Mohamed et al. 2010, Tian et al. 2013, Chhipa \& Kaushik 2017).

Fungal infection on Aquilaria tree had activated biochemical reactions and subsequently oleoresin was secreted until the agarwood formation was complete and ready to be harvested. As a natural defence mechanism response to these fungal outbreaks, normal heartwood was also found to be converted into dark agarwood (Akter et al. 2013). This suggested that the infected samples were light in colour at the early stages and slowly grew darker due to the accumulation of thick resin layers forming over time in order to protect against fungal infection. The resin increased the density and changed the wood colour from pale beige to dark brown or black. The deposition of resin had transformed the healthy wood into dense and dark wood (Naef 2011, Cui et al. 2013, Yusof et al. 2018). The two different colours in the infected sample region were correlated to the amount of accumulated resin during secretion by which the darker part displayed abundance resin accumulation (Chong et al. 2015). Furthermore, the dark region of the infected sample comprised agarwood resin and some dead parts of the tree due to the activation of cell death mechanism which also caused the dead regions to become dark in colour. Thus, it was suggested that the white region of infected samples may contain oleoresin accumulation without any dead tree parts which would the focus for the isolation of potential genes responsible towards biosynthesis of agarwood components.

Analysis of captured samples through Solid Phase Micro Extraction and Gas ChromatographyFlame Ion Detector data revealed that the A. malaccensis samples contained a complex mixture of chemical compounds including several sesquiterpene compounds (Figure 5). Analysis of sesquiterpene compounds that has been detected in infected white stems, infected black stems and healthy stems were recorded in Table 3. Based on the analysis, infected black stems recorded the most abundant sesquiterpene compounds among all samples. The infected white stems were considered the potential agarwood formation region as sesquiterpene compounds detected in infected white stems were higher than healthy stems. Analysis among the infected samples showed $\alpha$-bulnesene had high reading in infected black stems and highest reading in infected white stems at 6.03 and 7.92 respectively. The results corroborated the previous findings where high quality agarwood from A. malaccensis recorded the presence of $\alpha$-bulnesene as the highest percentage compound in wounded sample by artificial inoculant (Tajuddin et al. 2008).

There were distinct compounds detected in each collected samples regardless of agarwood origin and from different Aquilaria plants and 


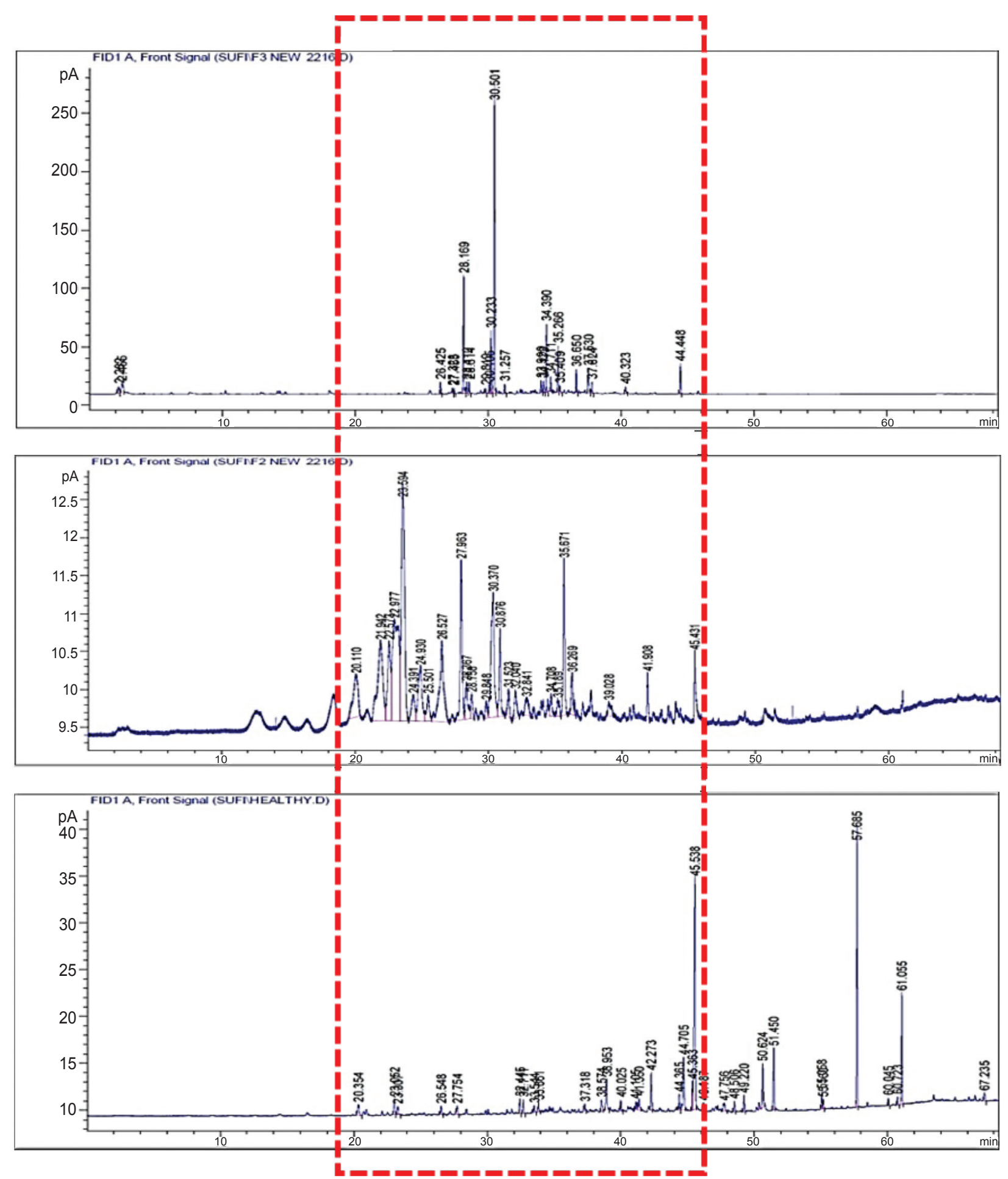

Sesquiterpene compounds were detected within area in the red box

Figure 5 Chromatogram of chemical compound comparison analysis for infected white (top), infected black (middle) and healthy stems (bottom) samples of A. malaccensis 
Table 3 List of sesquiterpene compounds detected in each of agarwood samples

\begin{tabular}{|c|c|c|c|c|}
\hline \multirow[t]{2}{*}{ Kovat's index } & \multirow[t]{2}{*}{ Compounds } & \multicolumn{3}{|c|}{ Area $(\%)$} \\
\hline & & Infected black & Infected white & Healthy \\
\hline 1210 & 4-phenyl-2-butanone & 0.47 & - & - \\
\hline 1414 & B-maaline & - & 7.24 & 0.82 \\
\hline 1443 & Aromadendrene & 0.14 & 7.36 & 0.9 \\
\hline 1472 & $\Upsilon$-gurjunene & - & 0.82 & \\
\hline 1486 & $\beta$-selinene & 0.35 & - & 1.58 \\
\hline 1496 & $\alpha$-muurolene & 0.42 & 0.63 & - \\
\hline 1503 & $\alpha$-bulnesene & 6.03 & 7.92 & - \\
\hline 1530 & $\alpha$-elemol & 1.05 & - & - \\
\hline 1553 & -agarofuran & - & 1.25 & \\
\hline 1557 & Norketoagarofuran & 0.26 & - & - \\
\hline 1572 & Epoxybulnesene & 0.17 & 1.16 & 1.17 \\
\hline 1600 & Caryophellene oxide & - & - & 0.75 \\
\hline 1603 & Guaiol & 1.44 & - & - \\
\hline 1608 & Y-eudesmol & 1.28 & - & - \\
\hline 1619 & 10-epi-Y-eudesmol & 6.94 & 0.99 & - \\
\hline 1631 & Agarospirol & 0.13 & - & \\
\hline 1640 & Epi- $\alpha$-cadinol & 4.89 & 0.8 & \\
\hline 1643 & Jinkoh-eremol & 0.81 & - & - \\
\hline 1650 & Kusunol & - & 5.15 & \\
\hline 1652 & $\alpha$-eudesmol & 0.33 & - & - \\
\hline 1664 & Bulnesol & 0.72 & - & - \\
\hline 1695 & Pentadecanal & 0.28 & - & 0.6 \\
\hline 1728 & Selina-4,11-dien-14-oic acid & - & - & 1.28 \\
\hline 1740 & 9,11-eremophiladien-8-one & - & - & 3.66 \\
\hline 1750 & Selina-3,11-dien-14-ol & - & 0.86 & \\
\hline 1770 & Guaia-1(10),11-dien-15-ol & - & 1.48 & \\
\hline 1782 & 2-hexadecanone & 0.9 & - & 24.15 \\
\hline 1806 & Guaia-1 (10),11-dien-15-al & - & - & 0.91 \\
\hline
\end{tabular}

shared some common general compounds. (Azah \& Ali 2012, Wang et al. 2018). The current findings revealed several potential sesquiterpene compounds which were related to high quality agarwood. High quality agarwood was believed to be enriched with aromatic and terpene compounds especially sesquiterpenes such as $\alpha$-guaiene, $\beta$-selinene, aromadendrene, $\alpha$-bulnesene and agarospirol (Yusof et al. 2018). The chemical components of agarwood were diverse and demonstrated different bioactivities and pharmacological properties (Wang et al. 2018). Revealing these valuable compounds had provided good information for more detailed future research on sesquiterpenes in agarwood.
Specific target study of the discovered agarwood sesquiterpenes may enhance the elucidation of new important metabolic synthases, thus contributing to the better scientific understanding of agarwood production.

\section{CONCLUSIONS}

A complete transcriptome analysis was conducted for three different region of stem samples of $A$. malaccensis including healthy, infected white and infected black stems. A total of 370,707 unigenes were functionally annotated. Chemical analysis showed both infected region of stem samples contained high readings of sesquiterpene 
compounds. The findings also highlighted the potential of the infected white stem region in promoting agarwood formation and the detection of high readings of sesquiterpene compounds. Further research on the infected white stems of A. malaccensis will facilitate deeper understanding in gene cloning, functional analysis of $A$. malaccensis as well as to detect the potential marker genes involved in the agarwood biosynthesis pathway.

\section{ACKNOWLEDGEMENT}

This project was funded by the Ministry of Higher Education, Malaysia (RDU130610) and Universiti Malaysia Pahang (RDU182207-1).

\section{REFERENCES}

Ahmaed DT, Mohammed M, Masaad AM et al. 2017. Investigation of agarwood compounds in Aquilaria malaccensis \& Aquilaria rostrata chipwood by using solid phase microextraction. Biomedical Journal of Scientific E Technical Research 1: 1-8.

Akter S, Islam MT, Zulkefeli M et al. 2013. Agarwood production - a multidisciplinary field to be explored in Bangladesh. International Journal of Pharmaceutical and Life Sciences 2: 22-32.

AzAH N \& Ali M. 2012. Analysis of agarwood oil (Aquilaria malaccensis) based on GC-MS data. Pp 470-473 in IEEE 8th International Colloquium on Signal Processing and Its Applications. 23-25 March 2012, Melaka.

Chen XM, Dong HL, Hu KX et Al. 2010. Diversity and antimicrobial and plant-growth-promoting activities of endophytic fungi in Dendrobium loddigesii Rolfe. Journal of Plant Growth Regulation 29: 328-337.

Chen H, Yang Y, Xue J et al. 2011. Comparison of compositions and antimicrobial activities of essential oils from chemically stimulated agarwood, wild agarwood and healthy Aquilaria sinensis (Lour.) Gilg trees. Molecules 16: 4884-4896.

ChнipA H \& Kaushik N. 2017. Fungal and bacterial diversity isolated from Aquilaria malaccensis tree and soil, induces agarospirol formation within 3 months after artificial infection. Frontiers in Microbiology 8: 1-12.

Cui J, Wang C, Guo S et al. 2013. Evaluation of fungusinduced agilawood from Aquilaria sinensis in China. Symbiosis 60: 37-44.

Chong SP, Osman MF, Bahari N et al. 2015. Agarwood inducement technology: a method for producing oil grade agarwood in cultivated Aquilaria malaccensis Lamk . Journal of Agrobiotech 6: -16.

Elias MF, Ibrahim H \& Mahamod WRW. 2017. A review on the Malaysian Aquilaria species in karas plantation and agarwood production. International Journal of Academic Research in Business and Social Sciences 7: 1021-1029.

Han XJ, Wang YD, Chen E et al. 2013. Transcriptome sequencing and expression analysis of terpenoid biosynthesis genes in Litsea cubeba. PLoS ONE 8: 1-15.
Huda AWN, Munira MAS, Fitrya SD \& Salmah M. 2009. Research article antioxidant activity of Aquilaria malaccensis (Thymelaeaceae) leaves. Pharmacognosy Research 1: 270-273.

Ismail N, RAHIMAN MHF, TAIB MN ET AL. 2013. Classification of the quality of agarwood oils from Malaysia using Z-score technique. Pp 78-82 in IEEE 3rd International Conference on System Engineering and Technology. 19-20 August 2012, Shah Alam.

Koffi MC, Vos C, Draye X eT AL. 2013. Effects of Rhizophagus irregularis MUCL 41833 on the reproduction of Radopholus similis in banana plantlets grown under in vitro culture conditions. Mycorrhiza 23: 279-288.

Liu B, Xue X, Cui S et AL. 2010. Cloning and characterization of a wheat b-1,3-glucanase gene induced by the stripe rust pathogen Puccinia striiformis $\mathrm{f}$. sp. tritici. Molecular Biology Reports 37: 1045-1052.

LiU Y, Wei J, GAO Z ET AL. 2017. A review of quality assessment and grading for agarwood. Chinese Herbal Medicines 9: 22-30.

Mazid M, Khan TA \& Mohammad F. 2011. Role of secondary metabolites in defence mechanisms of plants. Biology and Medicine 3: 232-249.

Mohamed R, Jong PL \& Zali MS. 2010. Fungal diversity in wounded stems of Aquilaria malaccensis. Fungal Divers. 43: 67-74.

NAEF R. 2011. The volatile and semi-volatile constituents of agarwood, the infected heartwood of Aquilaria species: a review. Flavour and Fragrance Journal 26: 73-89.

Nagajothi MS \& Parthiban KT. 2016. Fungal microbes associated with agarwood formation. American Journal of Plant Sciences 7: 1445-1452.

Nor-Azah MA, Saidatul-Husni S, Mailina J et al. 2013. Classification of agarwood (Gaharu) by resin content. Journal of Tropical Forest Science 25: 213-219.

Nor-FazILa K \& Ku-Halim KH. 2012. Effects of soaking on yield and quality of agarwood oil. Journal of Tropical Forest Science 24: 557-564.

Pojanagaroon S \& Kaewrak C. 2005. Mechanical methods to stimulate aloes wood formation in Aquilaria crassna Pierre ex H.Lec. (Kritsana) trees. Acta Horticulturae 676: 161-166.

SAIKIA P \& KHAN ML. 2011. Diversity of medicinal plants and their uses in home gardens of upper Assam, Northeast India. Asian Journal of Pharmaceutical and Biological Research 1: 296-309.

Schroeder A, Mueller O, Stocker S et Al. 2006. The RIN: an RNA integrity number for assigning integrity values to RNA measurements. BMC Molecular Biology $7: 1-14$.

Selosse M, Baudoin E \& Vandenkoornhuyse P. 2004. Symbiotic microorganisms, a key for ecological success and protection of plants. Comptes Rendus Biologies 327: 639-648.

Selvan TDN \& Kaushik-Pawan K. 2014. Agarwood production for intensive income generation. Review of Research 3:1-9.

Siah CH, Namasivayam P \& Mohamed R. 2016. Transcriptome reveals senescing callus tissue of Aquilaria malaccensis, an endangered tropical tree, triggers similar response as wounding with respect to terpenoid biosynthesis. Tree Genetics and Genomes 12: 1-10. 
Tabata Y, Widjaja E, Mulyaningsih T et al. 2003. Structural survey and artificial induction of aloeswood. Wood Research 90: 11-12.

Tajuddin SN, Muhamad NS, Yusoff MAY et al. 2008. Characterization of the chemical constituents of agarwood oils from Malaysia by comprehensive two-dimensional gas chromatography-time-offlight mass spectrometry. The Malaysian Journal of Analytical Sciences 12: 338-340.

Tan CS, Isa N, Ismail I et al. 2019. Agarwood induction: current developments and future perspectives. Frontiers in Plant Science 10: 1-13.

Thakur M \& Sohal BS. 2013. Role of elicitors in inducing resistance in plants against pathogen infection: a review. International Scholarly Research Notices. Article ID 762412, 10 pages. https://doi. org $/ 10.1155 / 2013 / 762412$

Tian J, GAO X, Zhang W ET AL. 2013. Molecular identification of endophytic fungi from aquilaria sinensis and artificial agarwood induced by pinholes-infusion technique. African Journal of Biotechnology 12: 3115-3131.

Van-Loon LC, Rep M \& Pieterse CMJ. 2006. Significance of Inducible Defense-related Proteins in Infected Plants. Annual Review of Phytopathology 44: 135-62.

WANG S, YU Z, WANG C ET AL. 2018. Chemical constituents and pharmacological activity of agarwood and Aquilaria plants. Molecules 23: 1-21.

Wong MT, SiAH CH, FARIDAH QZ eT AL. 2013. Characterization of wound responsive genes in Aquilaria malaccensis. Journal of Plant Biochemistry and Biotechnology 22: 1-8.

Wu ZQ, LiU S, Li JF ET AL. 2017. Analysis of gene expression and quality of agarwood using agar-bit in Aquilaria sinensis. Journal of Tropical Forest Science 29: 380-388.
Xu Y, Liao YC, Lv FF et al. 2017. Transcription factor AsMYC2 controls the Jasmonate-Responsive expression of ASS1 regulating sesquiterpene biosynthesis in Aquilaria sinensis (Lour.) Gilg. Plant and Cell Physiology 58: 1924-1933.

XU Y, Zhang Z, WANG M ET AL. 2013. Identification of genes related to agarwood formation: transcriptome analysis of healthy and wounded tissues of Aquilaria sinensis. BMC Genomics 14: 1-16.

Ye W, Wu H, He X eT AL. 2016. Transcriptome sequencing of chemically-induced Aquilaria sinensis to identify genes related to agarwood formation. PLoS ONE 11: 1-16.

Yusof S, Nizam S, Mansor R eT AL. 2018. Gas chromatography analysis of artificially inoculated agarwood compounds related to high quality agarwood from Malaysia plantation. Chemistry of Advanced Materials 3: 60-66.

Zhang Z, Yang Y, Meng H et AL. 2010. Advances in studies on mechanism of agarwood formation in Aquilaria sinensis and its hypothesis of agarwood formation induced by defence response. Chinese Traditional and Herbal Drugs 41: 156-159.

Zhang Z, Zhang X, Yang Y et al. 2014. Hydrogen peroxide induces vessel occlusions and stimulates sesquiterpenes accumulation in stems of Aquilaria sinensis. Plant Growth Regulation 72: 81-87.

Zhao J, Davis LC \& Verpoorte R. 2005. Elicitor signal transduction leading to production of plant secondary metabolites. Biotechnology Advances 23: 283-333. 